\title{
Assessing the Impacts of Electricity Utilization in Educational Faculties: A Thailand Case Study
}

\author{
Dalia M. M. Yacout ${ }^{1}$, Pramote Sirirote $^{2}$, M. M. Yacout ${ }^{3} \&$ Dusanee Thanaboripat $^{2}$ \\ ${ }^{1}$ Institute of Graduate Studies and Research, Alexandria University, Alexandria, Egypt \\ ${ }^{2}$ Faculty of Science, King Mongkut's Institute of Technology Ladkrabang, Bangkok, Thailand \\ ${ }^{3}$ Faculty of Agriculture, Alexandria University, Alexandria, Egypt \\ Correspondence: Dalia M. M. Yacout, Institute of Graduate Studies and Research, Alexandria University, \\ Alexandria, Egypt. Tel: 20-12-2130-6958. Email: dalia.yacout@gmail.com
}

The authors would like to thank the funded postdoctoral research grant for conducting this work by the Faculty of Science, King Mongkut's Institute of Technology (KMITL), Bangkok, Thailand.

Received: June 8, 2018

Accepted: June 27, 2018

Online Published: July 5, 2018

doi:10.20849/jess.v1i1.416

URL: https://doi.org/10.20849/jess.v1i1.416

\begin{abstract}
In view of the up-scaling energy crises worldwide, efforts have been focusing on reducing energy consumption and replacing fossil fuels usage with renewable energy sources. Thailand is one of the developing countries that have been facing an increase in energy demand associated to its economic expansion. The development in the educational sector is one of the sectors causing an increasing energy demand.

Purpose: This study aims to quantify energy usage and understand its environmental impacts in one of the educational facilities in Thailand in order to identify energy saving opportunities and improvement options related to energy consumption in this sector.

Materials and Methods: The investigation included a historical energy analysis for energy utilization of the facility, an onsite energy audit and an environmental impacts assessment. A number of potential energy saving opportunities was identified; related cost savings and $\mathrm{CO}_{2}$ reduction were calculated. Additionally, the environmental impacts of energy utilization were simulated using the life cycle assessment technique. Special attention was given to potential impacts on global warming due to its direct association to fossil fuels combustion.

Results and discussion: the pattern of energy utilization was identified and it clarified that the major contributor to energy utilization was energy consumption practices by students and staff of the faculty. Consequently, awareness raising of energy saving opportunities and people involvement was the major area of improvement. Results show that increasing people involvement in energy saving practices could lead to a cost saving of 46,000-120,000 USD/Year with low cost investment and a 100-240 ton $\mathrm{CO}_{2}$ reduction. Other potential savings were using motion sensors which save $30-40 \%$ of energy costs in offices and utilizing renewable solar energy as a source for electricity. This will save $13,300-33,300 \mathrm{USD} /$ Year with a 7.5 years payback and $35-50$ years lifetime.

When assessing the associated environmental impacts to electricity production, five main categories were found to be impacted: fossil fuels depletion, respiratory inorganics formation potential, global worming potential, acidification potential and eutrophication potential. The application of the suggested energy saving opportunities will reduce the electricity consumption, lower generated air emissions from fossil fuels combustion, consequently minimize all associated impacts specially global worming potential.

In Conclusion: assessing energy utilization of educational facilities is essential to reduce energy demand in an up-scaling economy. Energy analysis and onsite energy audits are efficient methods for recognizing energy utilization patterns and identifying energy saving opportunities. The implemented investigation in this study can be applied in different educational facilities.
\end{abstract}

Keywords: energy saving, electricity utilization, Thailand, global worming potentials 


\section{Introduction and Study-site Description}

Within the last decade, Thailand has been witnessing an up scaling economic development in the different sectors of the country including research and education. Electricity consumption is fundamentally associated to that development (IEA, 2016). In view of the up-scaling energy demand many efforts were conducted in order to optimize the energy usage in the different sectors of the country. In 2015, the Thailand Ministry of Energy launched a five energy policies plan called "Thailand Energy Integrated Blueprint-(TIEB)". Thailand Integrated Energy Blueprint reflects the goals to be achieved between 2015 and 2036. These goals are: to achieve energy supply security, cost competitiveness of energy, support energy sustainability, provide socio-economic support for the impacted people and reduce environmental impacts of energy utilization (Aggarangsi, 2017; Traivivatana et al., 2017). This study aims to analyze energy utilization in educational facilities in Thailand and assess its environmental impacts. Faculty of science, King Mongkut's Institute of Technology Ladkrabang (KMITL), Bangkok - Thailand was the case study of this investigation.

Faculty of science, KMITL is a public research and educational institution, located at Ladkrabang approximately $30 \mathrm{~km}$ east of the center of Bangkok. The faculty is one of the largest science faculties in Thailand and the second largest in KMITL. More than 4,000 students at undergraduate and postgraduate levels are registered in the faculty (KMITL, 2017). The faculty consists of six departments (Mathematics, Computer Science, Chemistry, Biology, Physics and Statics) and a Scientific instrument Center. The departments are distributed into 5 buildings, and the scientific instrument center is a separate building, in addition to an auditorium/conference hall building and a canteen with a food court area. The aim of the study was to assess and quantify electricity use and associated environmental impacts by the Faculty of science, KMITL. The objectives were to:

- Recognize electricity utilization pattern

- Identify electricity consumption sources

- Recommend energy saving opportunities

- Assess environmental impacts of energy utilization

2. Materials and Methods

\subsection{Data Collection}

In order to recognize energy consumption patterns and associated costs the following was collected: historical energy consumption data from 2013-2016 (last 4 Years), energy consumption invoices from 2013 -2016 (last 4 Years), facility layouts and equipment list.

\subsection{Onsite Energy Audit}

Through out May and June 2017 an onsite energy audit was conducted, the audit included all the buildings in the faculty of science, KMITL. During the audit interviews with students, administrative and academic staff members were done in order to recogniza their knowledge and involvement in energy saving practices.

\subsection{Environmental Impacts Assessment}

Assessing the enviromental impacts of electricity usage was done implementing life cycle assessemt (LCA) technique using the simulation software Sima Pro. LCA in this case starts from raw materials extration till the production of electricity. The impacts of energy usage were considered on human health, resources and ecosystem quality.

\section{Results and Discussion}

\subsection{Current Statues of Energy Consumption}

Electricity utilization was the main focus area in this study. Historical data for the electricity consumption was collected from 2013 till 2016, Table 1 and Figures 1-2.

Table 1 . Total electricity consumption from 2013 to 2016

\begin{tabular}{lcccc}
\hline Year & $2012 / 2013$ & $2013 / 2014$ & $2014 / 2015$ & $2015 / 2016$ \\
\hline Total consumption (kW) & $3,032,000$ & $2,758,000$ & $3,129,000$ & $3,453,000$ \\
Total Cost (USD) & 473,711 & 426,515 & 488,546 & 487,672 \\
\hline
\end{tabular}




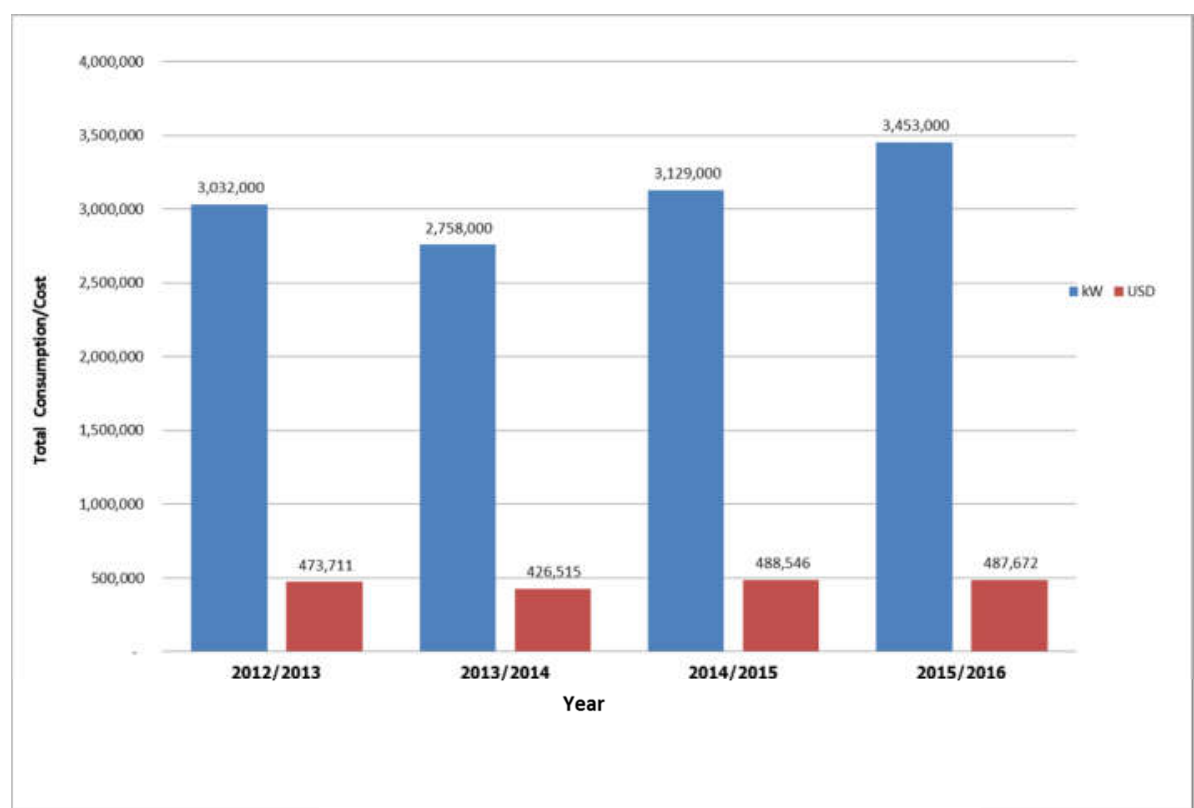

Figure 1. Energy consumption/cost data (Years 2013-2016)

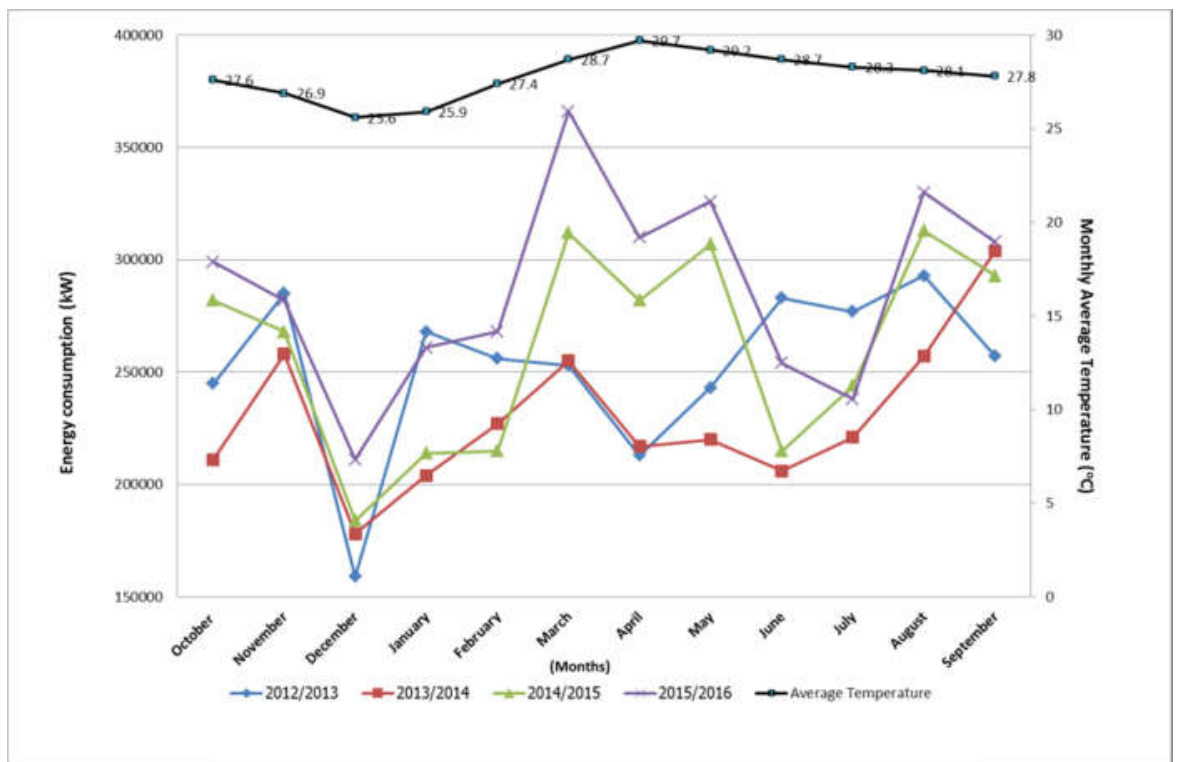

Figure 2. Monthly electricity consumption (Years 2013-2016)

Figure 2 shows the different electricity consumption patterns from 2013 to 2016 . The electicity consumption patterns differ due to the changes in the start and end of the acedemic years. In 2015 and 2016 the patterns of electricity consumption are similar as both years had simialr academic start and end dates. These patterns in electricity consumption are related to the people involvement "both students and staff". As following:

- Low electricity consumption during 6th of December till 8th January is related to the mid-semester holidays

- Low electricity consumption during late May till 1st week in August is due to summer holidays

- The 4 days public holidays causes the low consumption during middle of March.

Consequently, awareness raisins for people involvement is the first and most important energy saving opportunity. 


\subsection{Improvement Options}

\subsubsection{Awareness Raising and Increase People Involvement}

During the onsite audit many awareness posters related to energy saving were found in the different buildings, laboratories and offices. In spite of the large number of energy saving posters presenting the different energy saving opportunities and their benefits, low attention is paid by both students and staff on applying these practices. In most of the offices lights are constantly "ON" during working hours even if no one is available at the office. Lights, PCs and ACs are "ON" as well during lunch hour. Increasing both students and staff awareness and involvement can be done by:

a) A series of lectures about energy saving can be presented during the academic year for both students and staff members, b) Organize a big event related to energy like an "Energy saving day", announce for the event from the start of the academic year. Organize energy saving quizzes and competitions and celebrate the winners during the event. c) Start "Best energy saving competition for employees" encouraging them to apply different energy saving practices and suggest new ones each related to his/her workplace.

Energy saving potential from people involvement is a no cost investment, with a potential $10-25 \%$ saving in the energy consumption (William et al., 2003). In terms of money, the saving potential will be in case of $10 \%$ saving approx. 4,000-10,000 USD/Month, and 2-60 ton $\mathrm{CO}_{2}$ reduction. In case of $25 \%$ saving, 46,000-120,000 $\mathrm{USD} /$ Year, and 100-240 ton $\mathrm{CO}_{2}$ reduction.

\subsubsection{Lighting Sensors}

It was noticed that lighting of some hallways is usually "ON" during working hours even if the sun light is sufficient and there is no need for artificial lighting. It is receommened to use intelligent lighting detectors with motion sensors/occupational sensors that switches the lights automatically when a close motion is detected. Photo sensors can save up to 30-40\% of energy costs in offices (Berkeley, 2011).

\subsection{Solar Energy}

Thailand in general and Ladkrabang area in particular have high potentials for using solar energy (Solar GIS, 2012). Roofs, parking area as well as the front side and side walks and some buildings can be used for solar panels installations. The different opportunities identified for installing solar energy systems at the faculty of science, KMITL were summerized and presented in Table 2 and Figure 3. The potential savings for each area was calculated along with the related reduction in $\mathrm{CO}_{2}$ emissions and presented with each corresponding area. Usage of solar energy systems is considered a long term investment with high initial costs, however, the payback period of solar energy systems is approximately 7.5 years, and its life time ranges between $35-50$ years.

Table 2. Summery for potential solar energy system applications

\begin{tabular}{lccc}
\hline Opportunity & Area size $\left(\mathrm{m}^{2}\right)$ & Potential saving (USD) & $\mathrm{CO}_{2}$ reduction (Ton) \\
\hline Roof area (1) & 572 & 13333 & 100 \\
Roof area (2) & 572 & 13333 & 100 \\
Parking area & 150 & 3333 & 27 \\
Side walks & 90 & 2167 & 17 \\
Total & 1384 & 32167 & 244 \\
\hline
\end{tabular}




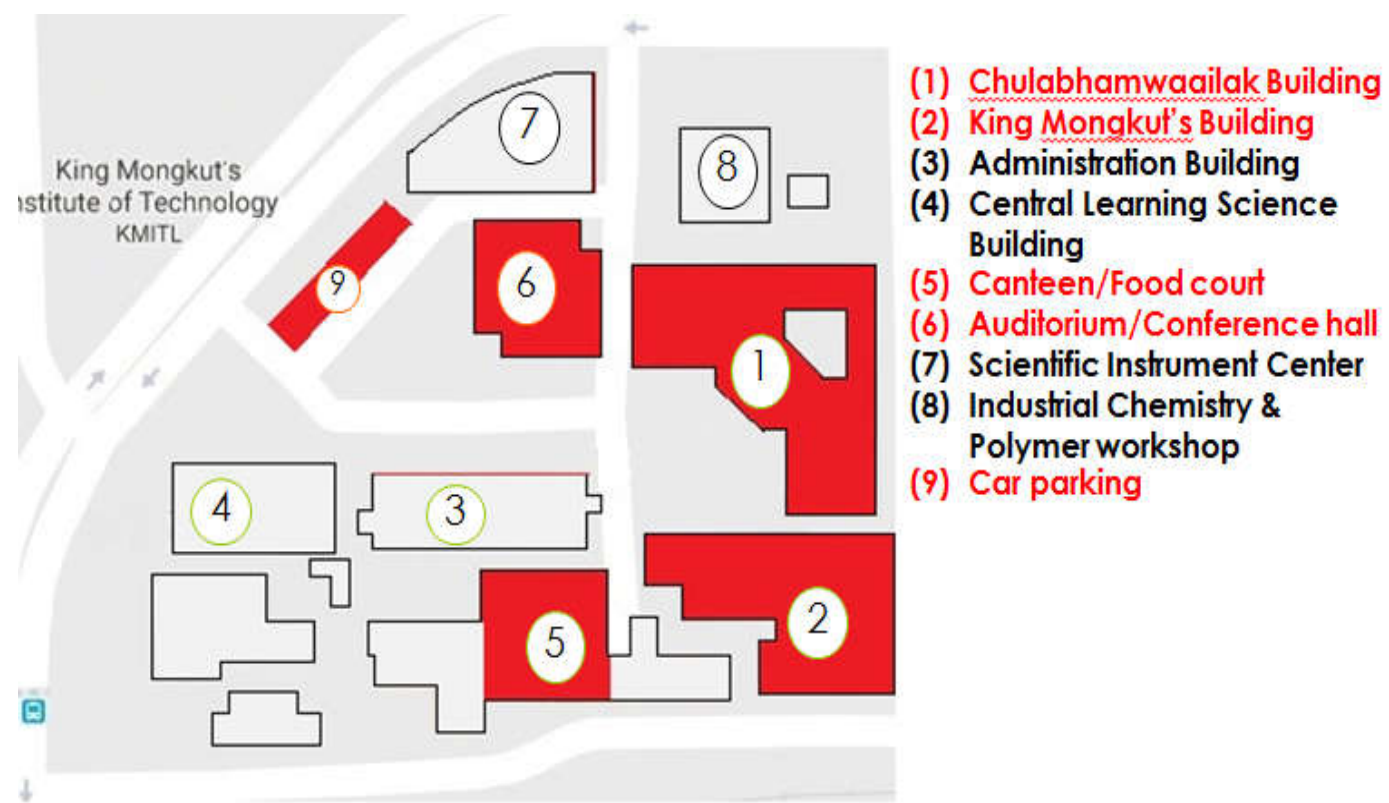

Figure 3. Potential solar energy installation areas-Faculty of Science, KMITL

\section{Environmental Assessment}

\subsection{Overall Impacts}

Assessing the enviromental impacts of electricity usage was done implementing the life cycle assessemt (LCA) technique. LCA in this case starts from raw materials extration till the production of electricity. The impacts of energy usage were considered on human health, resources and ecosystem quality.

Analysis results are shown in Figures 4-6. Highest impact is on resources in terms of fossil fuels depletion due to the usage of natural gas for electricity production. Next highest impacted category is human health in terms of respiratory iornagics formation potential due to the emitted emissions to air generated from fuel combustion.

Ecosystem quality was also impacted in terms of global warming potential indicated by climate change, acidfication and eutrohpiction potentials. Global warming potential is impacted due to carbon dioxide emissions generated from fuels combustion. As for acidfication and eutrohpiction potentials the released NOx and SOx from uncomleteped combusion were the main contributors to these impacts. 


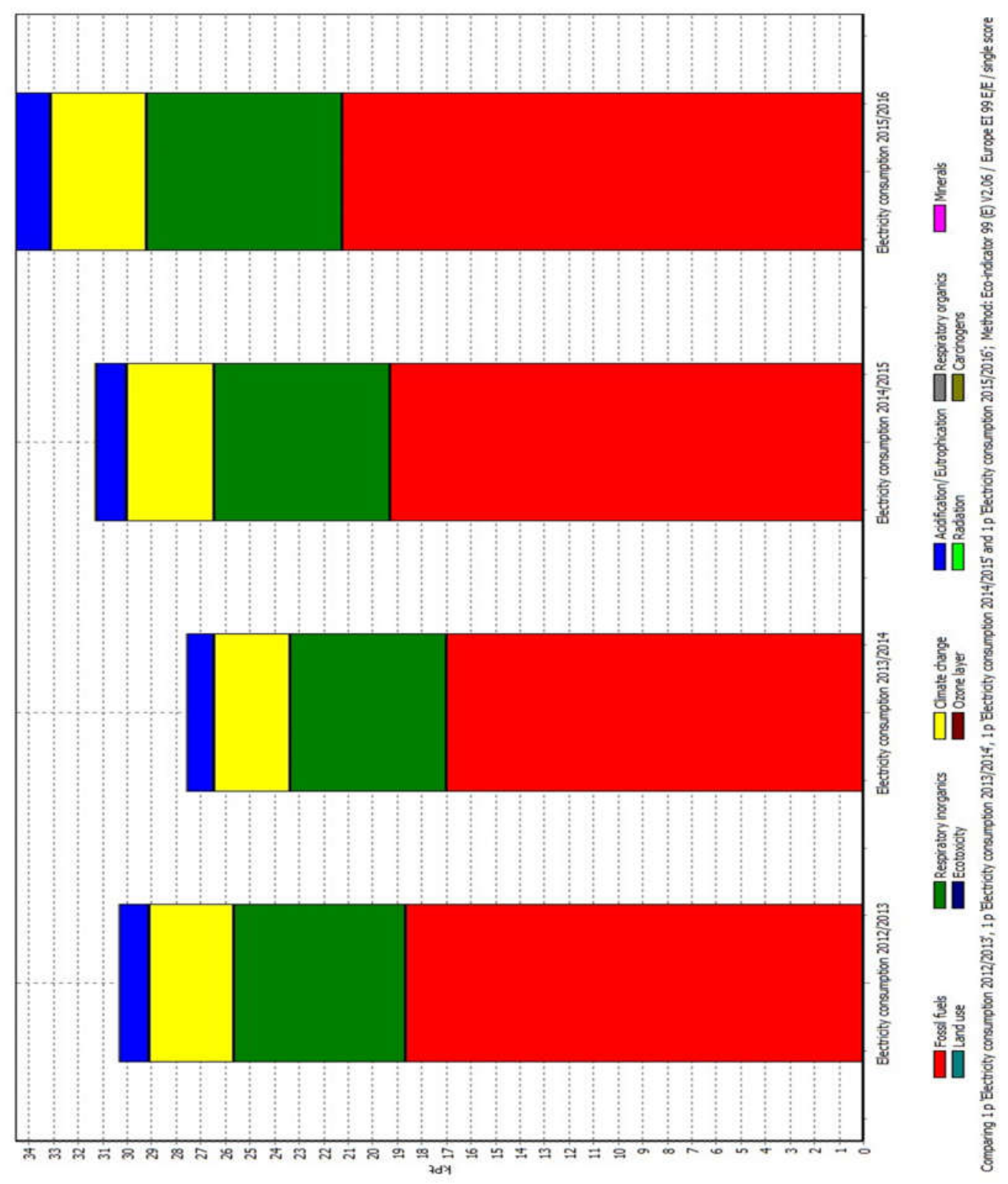

Figure 4. Environmental impacts of electricity consumption (Single score) 


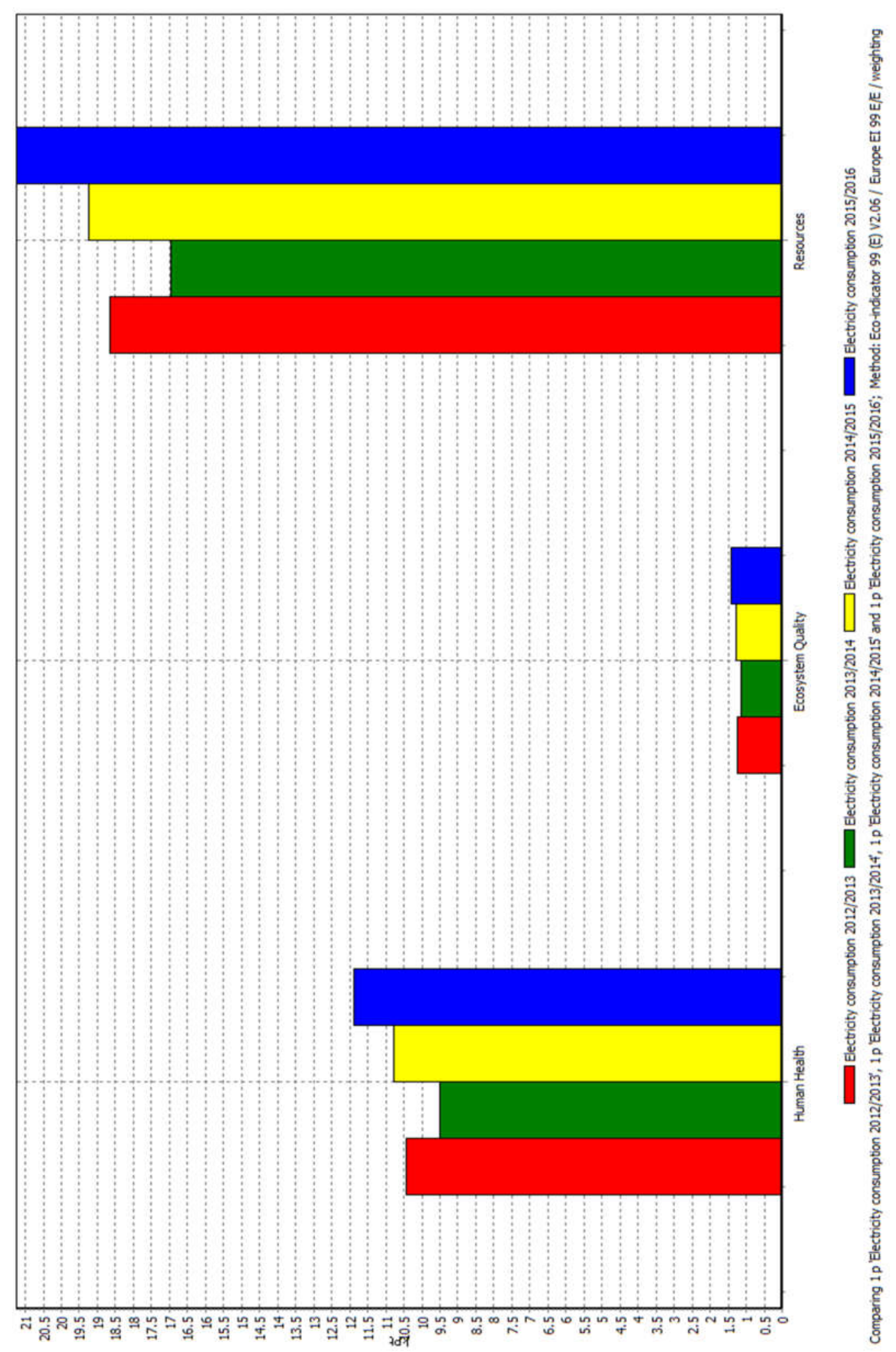

Figure 5. Environmental impacts of electricity consumption main categories 


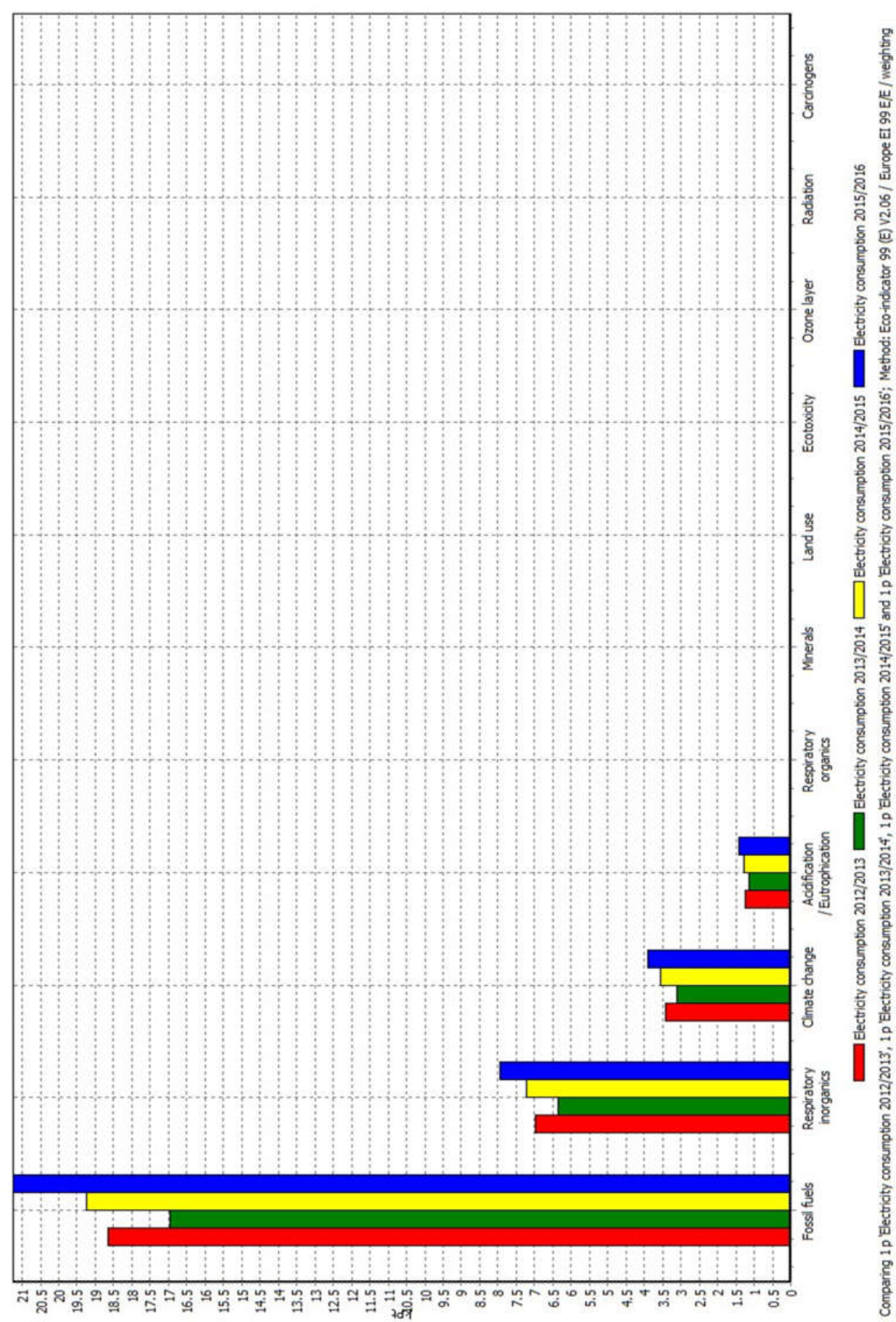

Figure 6. Environmental impacts of electricity consumption (weighting)

\subsection{Global Warming Potential}

Global warming potential (GWP) is one of the main concerns nowadays, and it is directly associated with electricity production and consumption. The generated emissions from fossil fuels combustion used for electricity production are the main contributor to GWP. Table 3 and Figure 7 show the quantity of generated $\mathrm{CO}_{2}$ 
due to the consumed electricity by faculty of science, KMITL. Reducing electricity consumption will lower generated air emissions, consequently minimize GWP.

Table 3. Carbon dioxide emissions from electricity production

\begin{tabular}{lccccc}
\hline \multirow{2}{*}{ Air Emission } & \multirow{2}{*}{ Unit } & \multicolumn{4}{c}{ Quantity per Year } \\
\cline { 3 - 6 } & & $2012 / 2013$ & $2013 / 2014$ & $2014 / 2015$ & $2015 / 2016$ \\
\hline Carbon dioxide & ton & 842.7 & 766.5 & 869.6 & 959.7 \\
\hline
\end{tabular}

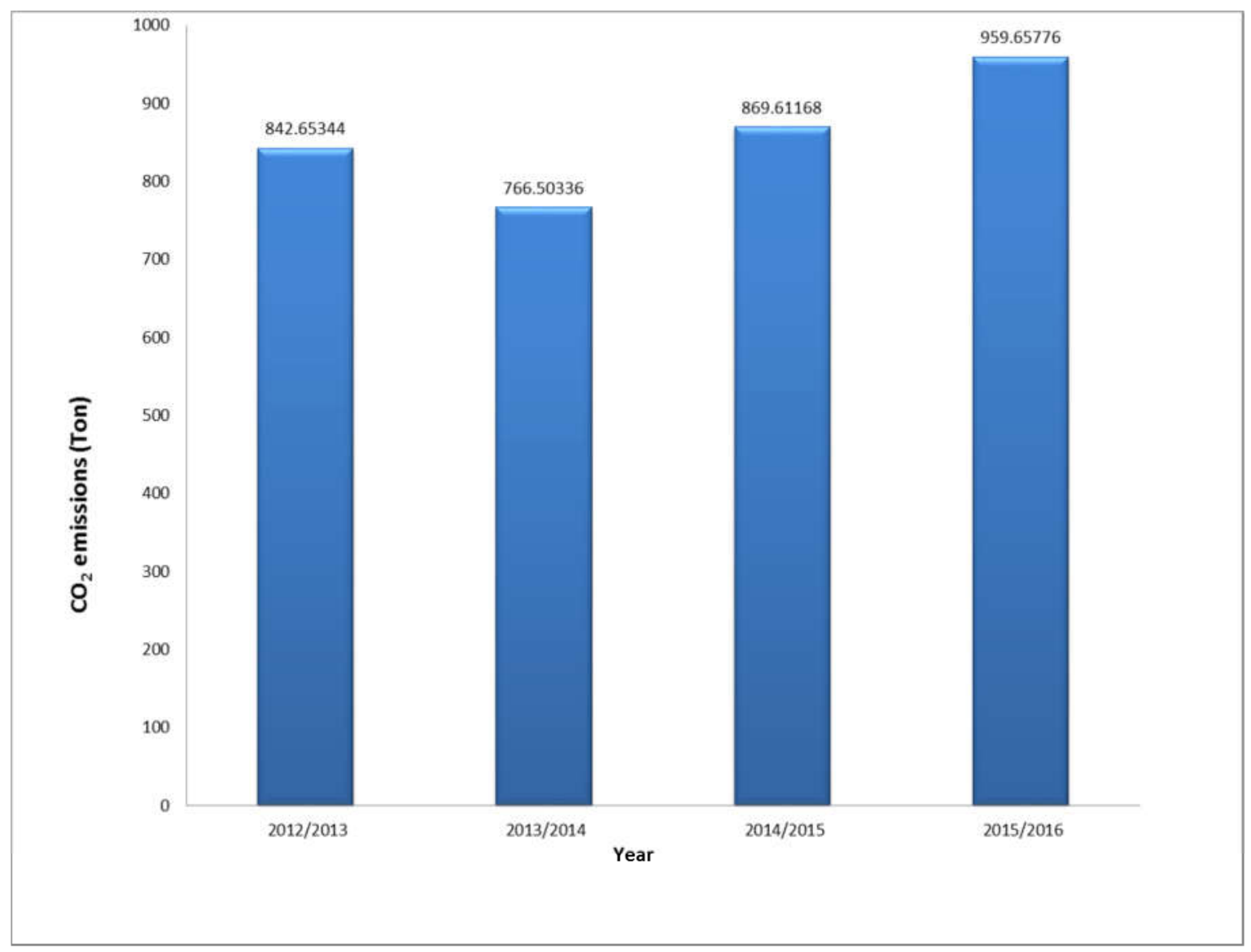

Figure 7. Carbon dioxide emissions from electricity production (Ton)

\section{Conclusion}

An assessment for energy utilization at the faculty of science, KMITL was conducted during May 2017. The assessment included an energy analysis, onsite energy audit and environmental impacts assessment. A number of suggestions were recommended to reduce energy consumption namely:

- Awareness raising about energy saving in the faculty and increase people involvement in energy saving issues. This will lead to a cost saving of 46,000-120,000 USD/Year, and 100-240 ton $\mathrm{CO}_{2}$ reduction with low cost and payback in the same year

- Using motion sensors which will save $30-40 \%$ of energy costs in office

- Utilizing solar energy for electricity generation and consumption, will save $32167 \mathrm{USD} /$ Year and mitigate the generation of 244 ton $\mathrm{CO}_{2}$. The used solar system has a 7.5 years payback duration and 35-50 years lifetime

Electricity production and consumption have many environmental impacts mainly on fossil fuels depletion, Respiratory inorganics formation potential, global worming potential, acidification potential and eutrophication 
potential. Reducing electricity consumption will lower the generated air emissions, consequently minimize all associated impacts, especially GWP.

Finally, it is recommended to: a) conduct a more detailed energy audit at the faculty of science, KMITL including all existing equipment, laboratory and offices to identify more improvement options. b) assess the energy consumption and apply an onside energy audit on an annual basis in order to monitor the energy consumption pattern and improve statues of energy utilization. The applied assessment for energy utilization in this study can be implemented in similar cases in the educational sector worldwide.

\section{References}

Aggarangsi P. (2017, November 20). Current Status and Opportunity of Biogas Industries in Thailand. Thai German Technology Conference; Biogas. Bangkok.

Berkeley L. (2011). A Meta-Analysis of Energy Savings from Lighting Controls in Commercial Buildings, National Laboratory and Erik Page \& Associates.

Energy Advisor. (2003). Lighting: Occupancy Sensors, Florida Power and Light. Occupancy Sensor Vendors include: Watt Stopper, Sensor Switch, Novitas and Leviton. Retrieved from http://www.fpl.com/savings/energy_advisor/PA_10.html

IEA (International Energy Agency). (2016). Thailand Electricity Security Assessment 2016. Paris Cedex, France. Solar GIS, 2012. Retrieved from https://solargis.info/

Kennedy, W. J., Wayne, C. T., \& Barney, L. C. (2003). Guide to energy management (4th ed.). The Fairmont Press.

KMITL (Faculty of Science KMITL). (2017). Retrieved from http://sci-en.kmitl.ac.th/

Traivivatana, S., et al. (2017, May 25-26). Thailand Energy Procedia, 138, 399-404. 2017 International Conference on Alternative Energy in Developing Countries and Emerging Economies 2017 AEDCEE, Bangkok. https://doi.org/10.1016/j.egypro.2017.10.179

William, J. K., Turner, W. C., \& Capehart, B. L. (2003). Guide to Energy Management (4th ed.). USA: The Fairmont Press, Inc.

\section{Copyrights}

Copyright for this article is retained by the author(s), with first publication rights granted to the journal.

This is an open-access article distributed under the terms and conditions of the Creative Commons Attribution license (http://creativecommons.org/licenses/by/4.0/). 